\title{
SPEED CONTROL OF BRUSHLESS D.C. MOTOR USING SIX PULSE CONVERTER
}

\author{
Midde Mahesh ${ }^{1}$ and K. Leleedhar Rao ${ }^{2}$
}

\begin{abstract}
This paper presents speed control of permanent magnet brushless dc motor using 6 Pulse operations. According to the input command, feedback and the control algorithm, the pulse for each phase are generated and is given to the IGBT driver. The output of the driver is 6 independent pulses that have to be given to the corresponding gates of the six IGBTs power switches used in the three-phase bridge inverter whose output is given to the stator of the Brushless DC Motor. The complete system model is simulated in MTALAB software.

Keywords - Brushless DC Motor, Pulse Operation., DC drive
\end{abstract}

\section{INTRODUCTION}

Brushless DC motors are also known as electronically commutated motors. Electronic Commutated motors are synchronous electric powered by direct current (DC) electricity and having electronic commutation systems, rather than mechanical commutator and brushes. The brushless DC motor can be envisioned as a brush DC motor turned inside out, where the permanent magnets are on the rotor, and the windings are on the stator. As a result, there are no brushes and commutator in this motor, and all of the disadvantages associated with the sparking of brush DC motors are eliminated.

This motor is referred to as a "DC" motor because its coils are driven by a DC power source which is applied to the rotor and a rotating magnetic field induced in the wound stator poles. In this example there are three electromagnetic circuits connected at a common point. Each electromagnetic circuit is split in the center, thereby permitting the permanent magnet rotor to move in the middle of the induced magnetic field. Most BLDC motors have a three -phase winding topology with star connection. A motor with this topology is driven by energizing 2 phases at a time.

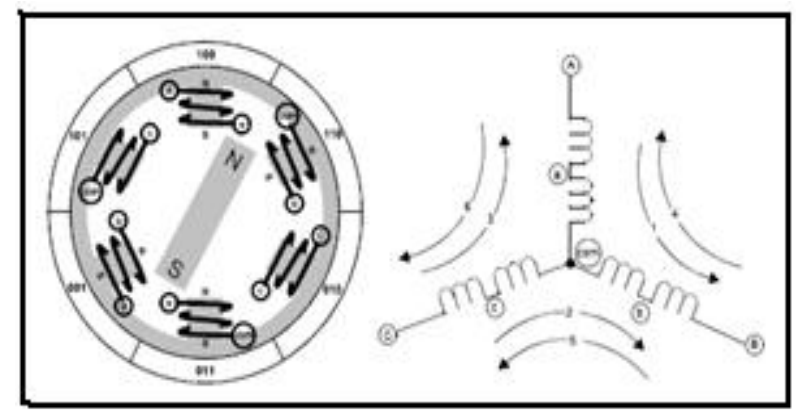

Figure-1. BLDC motor construction

${ }^{1}$ Department of Electrical and Electronics Engineering J.N.T.U.A. COLLEGE OF ENGINEERING, Anantapuramu515002, Andhra Pradesh, INDIA

${ }_{2}^{2}$ Department of Electrical and Electronics Engineering SREE VIDYANIKETAN ENGINEERING COLLEGE, Tirupati-517102, Andhra Pradesh, INDIA 
However; "BLDC" is really a misnomer, since the motor is effectively an AC motor. The current in each coil alternates from positive to negative during each electrical cycle. The stator is typically a salient pole structure which is designed to produce a trapezoidal back-EMF wave shape which matches the applied commutated voltage waveform as closely as possible. However, this is very hard to do in practice, and the resulting back-EMF waveform often looks more sinusoidal than trapezoidal. For this reason, many of the control techniques used with a PMSM motor (such as Field Oriented Control) can equally be applied to a BLDC motor.

Brushless DC motors use an electronic controller which regulates and controls the voltage and current to the field coils. The electronic module or controller uses discrete devices and amplifiers to establish and deliver the desired voltage/current. Advantages of a brushless motor include, increased reliability, longer life, elimination of sparks from the commutator, reduced friction, precision voltage/current applied to the field coils, faster rate of voltage and current.

\section{A. Anatomy of a BLDC}

Figure 1 is a simplified illustration of BLDC motor construction. A brushless motor is constructed with a permanent magnet rotor and wire wound stator poles. Electrical energy is converted to mechanical energy by the magnetic attractive forces between the permanent magnet. An interesting property of brushless DC motors is that they will operate synchronously to a certain extent. This means that for a given load, applied voltage, and commutation rate the motor will maintain open loop lock with the commutation rate provided that these three variables do not deviate from the ideal by a significant amount. The ideal is determined by the motor voltage and torque constants. Consider that when the commutation rate is too slow for an applied voltage, the BEMF will be too low resulting in more motor current. The motor will react by accelerating to the next phase position then slow down waiting for the next commutation. In the extreme case the motor will snap to each position like a stepper motor until the next commutation occurs. Since the motor is able to accelerate faster than the commutation rate, rates much slower than the ideal can be tolerated without losing lock but at the expense of excessive current. Now consider what happens when commutation is too fast. When commutation occurs early the BEMF has not reached peak resulting in more motor current and a greater rate of acceleration to the next phase but it will arrive there too late. The motor tries to keep up with the commutation but at the expense of excessive current. If the commutation arrives so early that the motor cannot accelerate fast enough to catch the next commutation, lock is lost and the motor spins down. This happens abruptly not very far from the ideal rate. The abrupt loss of lock looks like a discontinuity in the motor response which makes closed loop control difficult. An alternative to closed loop control is to adjust the commutation rate until self locking open loop control is achieved. This is the method we will use in our application. When the load on a motor is constant over its operating range then the response curve of motor speed relative to applied voltage is linear. If the supply voltage is well regulated, in addition to a constant torque load, then the motor can be operated open loop over its entire speed range.

Key characteristics of the Variable Speed Brushless DC Motor

Synchronous external commutation

No brush noise, Durable \& Robus

Flat Speed Vs Torque Characteristics

Position/Speed Servo

\section{CIRCUIT}

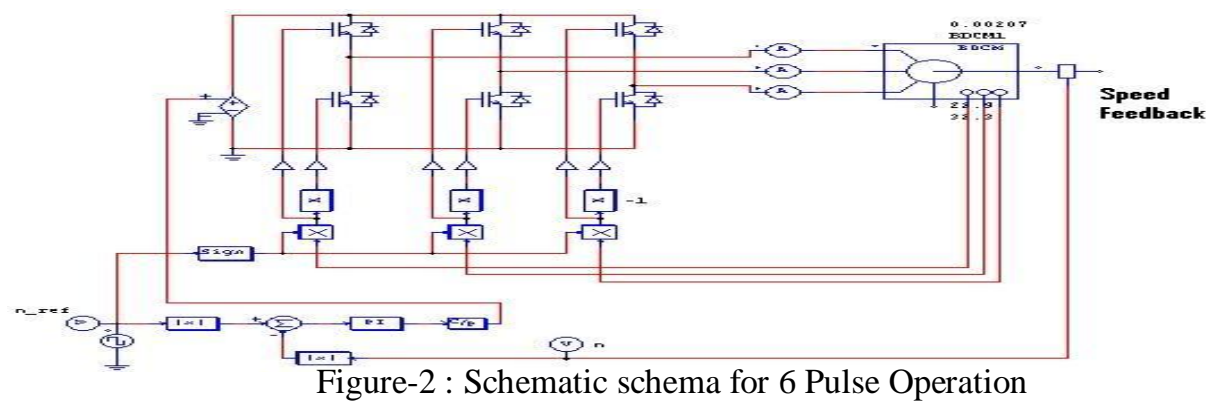


The circuit consists of a voltage controlled voltage source connected across three phase IGBT Bridge An IGBT consists of a transistor in anti-parallel with a diode. It is turned on when the gating is high and the switch is positively biased. It is turned off when the gating is low or the current drops to zero. The gate node of the IGBT can be connected to a switch gating block GATING or the output of a switch controller only. The on-off switch controller interfaces between the control circuit and the power circuit. The input is a logic signal ( 0 or 1$)$ from the control circuit. The output is connected to the gate (base) node of a switch (or multiple switches) to control the conduction of the switch. The signal level of 1 is for switch on and 0 for switch off. This bridge is connected to Brushless dc motor whose speed feedback system is closed loop with negative feedback, and finally this feedback controls the input voltage source. Thus this circuit shows similarity in characteristics between Brushless dc motor and conventional dc motor. Thus by changing the dc bus voltage speed can be controlled.

The BLDC motor also consists of a Hall position sensor embedded in its stator. A Hall Effect position sensor consists of a set of hall switches and a set of trigger magnets. The hall switch is a semiconductor switch (e.g. MOSFET or BJT) that opens or closes when the magnetic field is higher or lower than a certain threshold value. It is based on the Hall Effect, which generates an emf proportional to the flux-density when the switch is conducting a current supplied by an external source. It is common to detect the emf using a signal conditioning circuit integrated with the hall switch or mounted very closely to it. This provides a TTL-compatible pulse with sharp edges and high noise immunity for connection to the controller via a screened cable. For a three-phase brushless dc motor, three hall switches are spaced 120 electrical deg. apart and are mounted on the stator frame. The set of trigger magnets can be a separate set of magnets, or it can use the rotor magnets of the brushless motor. If the trigger magnets are separate, they should have the matched pole spacing (with respect to the rotor magnets), should be mounted on the shaft in close proximity to the hall switches. If the trigger magnets use the rotor magnets of the machine, the hall switches must be mounted close enough to the rotor magnets, where they can be energized by the leakage flux at the appropriate rotor positions.

\section{SIMULATION RESULTS}

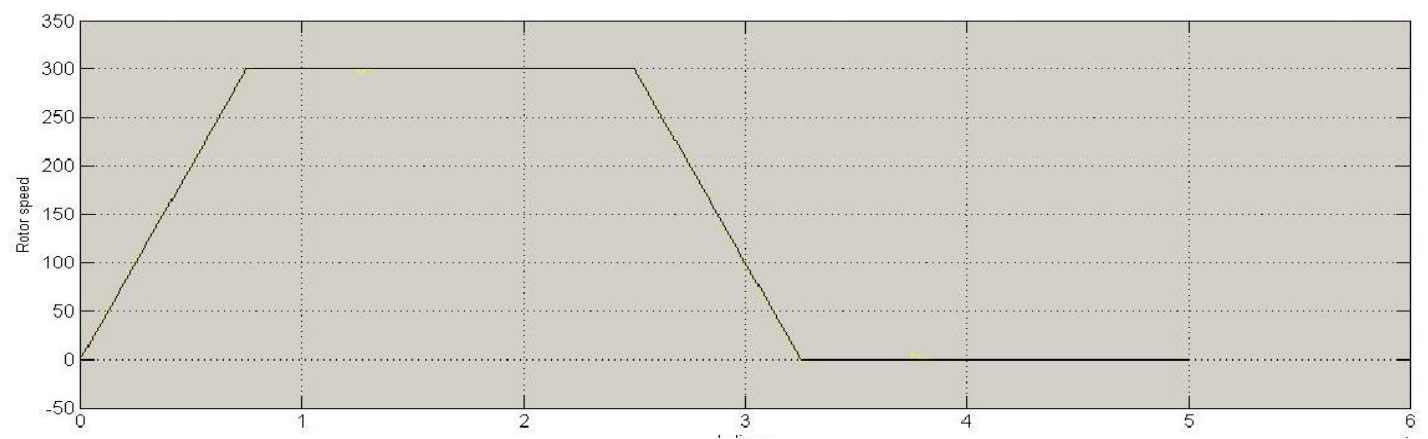

Fig(3): Speed vs Time

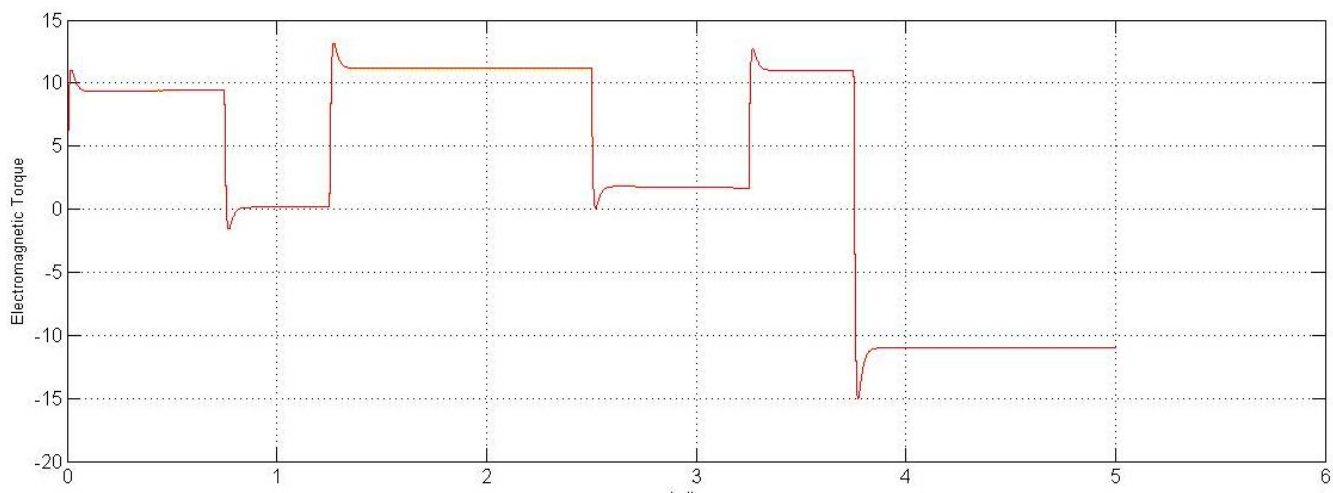

Fig(4): Electromagnetic Torque Characteristic 


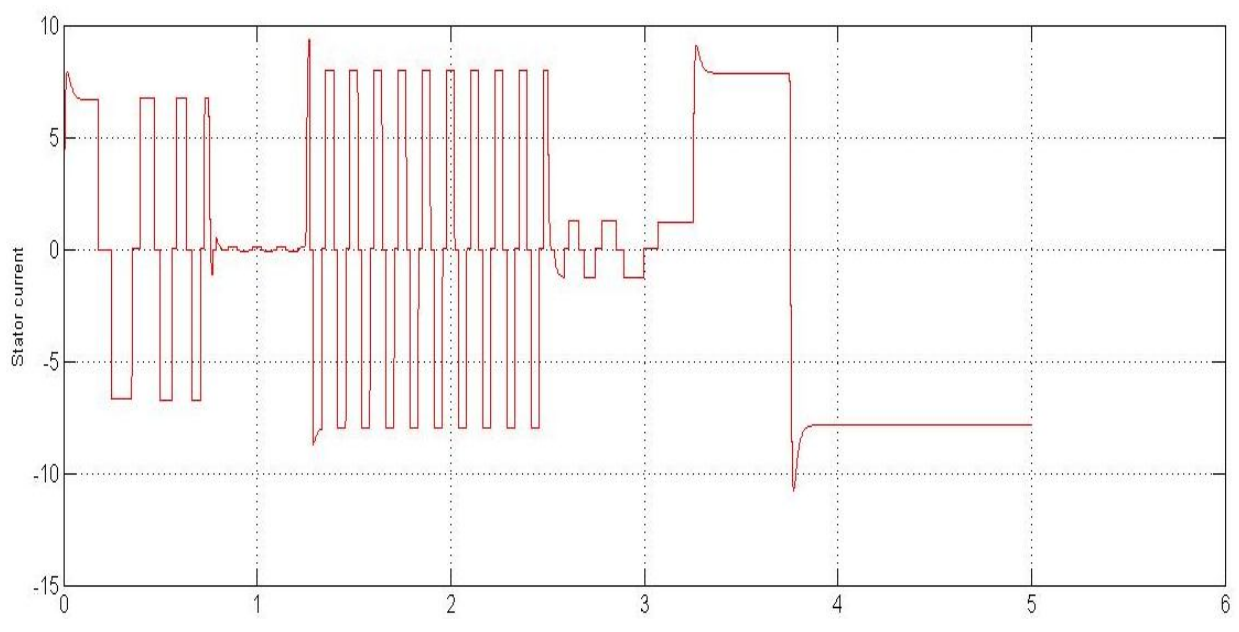

A. Brushless DC Characteristics

Fig(5): Stator Current

Voltage on the motor determines speed and current in the motor determines torque. These relationships are linear and nearly identical to a standard Brush DC drive. The application of the product then is essentially like the more familiar brush machine. Speed accuracy is very high, in fact with the most widely used Brushless drive, the accuracy is synchronous ( $0 \%$ speed error) due to a digital encoder and drive controller position regulation. Torque to inertia ratios are very high providing high accel/decel rates and excellent dynamic response. Controller bandwidth (30 to $40 \mathrm{~Hz}$ ) is 5 to 8 times higher [7] than the Brush DC drive. Motor efficiencies range from 90 to $96 \%$ and controller efficiency is $97 \%$ giving overall efficiencies better than brush DC systems.

\section{B. Advantages}

In general, the characteristics of Brushless D.C. that are most advantageous to the blow molding process are:

- Very precise average speed control over a very wide speed range.

- Precise instantaneous speed control due to high dynamic response

- Constant power factor means lowest possible input current.

- Small physical size of motor compared to brush type.

- No recurring motor maintenance (brush replacement)

- Feedback device (encoder) is inside the motor not outside.

- Higher efficiency overall.

The blow molding process always involves an extruder of some kind and the variable speed drive on the extruder has to provide an output sufficient to allow the comparison to be formed in time to meet the cycle requirements. Since the final product may require more or less volume of plastic for different shapes and because the cycle time varies, hence the requirement for variable speed. The result of inconsistent speed control is simply that more (or less!) material than is necessary to make the part will be extruded. Speed control consistency therefore is important to the production of a consistent product. Speed that either drifts slowly.

\section{SUMMARY AND CONCLUSIONS}

While there are several options available to the manufacturer and user regarding the type of variable speed drive to use on the Extruder and rotating mold applications of the blow molding machine, there are some distinct advantages in the use of the Brushless D.C. drive while other types of drives may become available in the future that may provide these advantages, they are not yet available for general use in the HP sizes necessary for most blow molding machines. The Brushless DC technology is here and in wide use in various extrusion and related applications in the plastics industry. 


\section{REFERENCES}

[1] T.G. Wilson, P.H. Trickey, "D.C. Machine With Solid State Commutation", AIEE paper \# CP62-1372, Oct 7, 1962.

[2] NEMA Publication \# MG 1, ref MG-1.41.2, table 12.6B

[3] Eaton Dynamatic Electric Drive Applications Guide page M-37.

[4] Dennis P. Connors, Dennis A. Jarc, Roger H. Daugherty, "Considerations in Applying Induction Motors with Solid-State Adjustable Frequency Controllers",IEEE Transactions on Industry Applications, Vol 1A20, no.

1, January/February, 1984.

[5] John B. Mitchell, "Inverter Power Factor and Noise", Power Transmission Design magazine, page $45,46$.

[6] Derek A. Paice, "Harmonic Issues and Clean Power Controllers", Westinghouse Electric Corp, Presented at PCIM '90, Oct 25, 1990.

[7] Frank J. Bartos, "Reliability, Ease of Use Widen AC Drives' Application Horizons", Control Engineering News, page 55, February 1992.

[8] Robert E. Lordo, "Comparison of the $150 \mathrm{HP}$ Brushless DC and conventional DC/SCR motor/Control", June, 1992, POWERTEC Industrial Corp. Box 2650, Rock Hill, S.C. 29732, phone 803-328-1888 